\title{
Condorcet Voting Theory based on Analytical Hierarchy Process (AHP) for Project Selection Problems
}

\author{
Nor Faradilah Mahad ${ }^{1^{*}}$, Nur Ain Shahidah Mohd Azli ${ }^{1}$, Nur Anis Fatihah Razalli ${ }^{1}$ and Noor Nadhirah \\ Mohd Nor Azmi ${ }^{1}$ \\ ${ }^{1}$ Universiti Teknologi MARA Cawangan Negeri Sembilan, Kampus Seremban, Persiaran Seremban \\ Tiga/1, Seremban 3, 70300 Seremban, Negeri Sembilan, Malaysia
}

\begin{abstract}
Project selection is a process of evaluating a set of proposals and hence selecting the most potential project to be completed. This process is a challenging task for decision makers since the process involves many conflicting criteria and due to the limited resources, not all the projects can be implemented. Therefore, Condorcet Voting Theory based on Analytical Hierarchy Process (AHP) method is used to solve the project selection problems. The Condorcet Voting Theory based on AHP is a method to solve the multicriteria decision making (MCDM) problems where the voters will cast their votes to choose between two candidates. The quantitative ratio of the votes given to the candidates will be further used to construct the pairwise comparison matrix instead of the 9-points Saaty scale in the traditional AHP approach. The objectives of this study are to solve the project selection problems using Condorcet Voting Theory based on AHP method and to do comparison between AHP method and Condorcet Voting Theory based on AHP method. A real-life empirical data on the factors that contribute to road accidents was used to demonstrate the application of Condorcet Voting Theory based on AHP method. Decision makers will be able to make a judgment in a simple way by using voting method as the decision makers or the voters will cast their votes to select or not to select the alternatives.
\end{abstract}

Keywords: Condorcet Voting Theory, Analytical Hierarchy Process (AHP), multi-criteria decision making (MCDM)

\section{INTRODUCTION}

Every project has its own purpose, cost, budget, benefit, and risk. Not all the projects can be implemented. It is very crucial for the decision maker(s) to select the most potential project among a list of proposals due to the limited resources faced by organization. The goal of the project selection process is to analyze project viability and to approve or to disapprove project proposals based on established criteria, following a set of structured steps and checkpoints (Amiri, 2010). Since this process involved many conflicting criteria, the project selection problems are also part of multi-criteria decision making (MCDM) problems. MCDM is the process of evaluating a set of alternatives and selecting the best alternatives based on the multiple criteria that are often in conflict. MCDM tools can be used to sort a set of alternatives from the most preferred to the least preferred one based on their relative weight. The criteria used to evaluate the alternatives can be either quantitative or qualitative, and the knowledge of the consequences of the decisions is always limited (Nowak, 2013).

Analytical Hierarchy Process (AHP) method is one of the most popular MCDM method. AHP is a theory of relative measurement on absolute scales of both tangible and intangible criteria based on paired comparison judgment of knowledgeable experts (Ozdemir \& Saaty, 2006). AHP is easier to understand and it can be used to evaluate qualitative and quantitative data. It helps decision makers to find the best solution that suit their goal and their understanding of the problem. 
AHP is rigorously concerned with the scaling problem and what sort of numbers to use, and how to correctly combine the priorities resulting from them (T. L. Saaty, 1990). Sometimes it is difficult to determine how many times more strongly one element is over another element when they are compared. For example, if a decision maker thinks that $\mathrm{A}$ is more important that $\mathrm{B}$, the question is how much more important A compared to B? To overcome the shortcoming, a voting method is applied to ease the decisionmaking process.

The Condorcet Voting Theory Based on AHP (Condorcet-AHP) method is the combination between Condorcet Voting Theory and the traditional AHP method. Condorcet Voting Theory is a pair-wise comparison method designed by Marquis de Condorcet, a famous philosopher and mathematician (Bhattacharya \& Raju, 2017). In the Condorcet voting algorithm, the voters will cast their votes to choose one between two candidates based on their preferences. If one candidate is preferred than the other, the candidate will score a point and the votes with equal priority will be eliminated from the computation (Bhattacharya \& Raju, 2017).

The quantitative ratio derived from the pairwise comparison between two potential candidates will be further used to frame the judgment matrix in the traditional AHP approach instead of the Saaty scale. The AHP method is then used to compute the relative weight for criteria or alternatives.

This paper focuses on the application of Condorcet-AHP approach to solve projection selection problems. The objectives of the study are to solve the project selection problems using Condorcet-AHP method, and to do comparison between AHP method and Condorcet-AHP method. A real-life empirical data on the factors that contribute to road accidents was used to demonstrate the application of AHP and Condorcet-AHP method. This paper is divided into 7 sections which are Introduction, Literature Review, Methodology, Data Analysis, Result and Discussion, Conclusion and Acknowledgement.

\section{LITERATURE REVIEW}

\section{A. Analytical Hierarchy Process}

AHP is a theory of measurement through pair-wise comparison and depends on the judgment of experts to attain priority scale (T. L. Saaty, 2008). AHP involves the principles of decomposition, comparative judgment of the alternatives and the criteria and synthesis of the priorities (Vinod Kumar \& Ganesh, 1996; Amiri, 2010).

The process starts with decomposing the complex MCDM problem hierarchically. The hierarchical structure consist of a goal, a set of criteria or sub-criteria (if any) and a set of alternatives are positioned in a hierarchical structure similar to a family tree (Amiri, 2010). The objective or the goal of the problems is placed at the top level, the criteria and the sub criteria (if any) in middle level and lastly the alternatives at the bottom level of the structure. The structure of hierarchy is linear and proceeds downward from the most general and less controllable (goals, objectives, criteria, sub criteria) to the more concrete and controllable factors terminating in the level of alternatives (T. L. Saaty, 1994).

The second principle is about comparing pairs of elements in each level with respect to every element in the next higher level using Saaty scale (Vinod Kumar \& Ganesh, 1996).

The third principle is synthesizing the priorities. The priorities are synthesized by comparing the importance of the criteria with respect to higher level criteria or with respect to a goal, and as above, derive priorities for the alternatives with respect to each criterion. Lastly, the normalized priorities of the alternatives is multiplied by the corresponding normalized priorities of the criteria and add to compute the overall ranking of the alternatives ( Saaty \& Vargas, 2013; Saaty, 1987).

\section{B. Condorcet Voting Theory Based on AHP}

The Condorcet method is an election method where each voter will cast their votes to choose the best candidates using pair wise comparison. Condorcet proposed that whenever a candidate obtains a simple majority over every other candidate, then that candidate is presumptively the "best" (Young, 1988). Thus, Condorcet Voting Theory is a voting method that satisfies the majority criterion in a pairwise comparison if a candidate with majority votes wins the election.

Bhattacharya and Raju, (2017) suggested that in the Condorcet-AHP method, each voter will determine the importance of a criterion over the other by voting and then use of a quantitative ratio-based approach to set up the pair 
wise comparison matrix instead of the Saaty scale shown in Table 1. Each vote casted means a point. Any votes with equal priority given to both criteria are eliminated from consideration.

Once the pairwise comparison matrix is set up, the AHP method will be used to determine the weight of the criteria and alternatives.

Table 1. The fundamental scale of absolute numbers (T. L. Saaty \& Vargas, 2013)

\begin{tabular}{|c|c|c|}
\hline $\begin{array}{l}\text { Intensity of } \\
\text { importance }\end{array}$ & Definition & Explanation \\
\hline 1 & Equal importance & Two activities contribute equally to the objective \\
\hline 2 & Weak & \\
\hline 3 & Moderate importance & $\begin{array}{l}\text { Experience and judgment slightly favour one activity } \\
\text { over another }\end{array}$ \\
\hline 4 & Moderate plus & \\
\hline 5 & Strong importance & $\begin{array}{l}\text { Experience and judgment strongly favour one activity } \\
\text { over another }\end{array}$ \\
\hline 6 & Strong plus & \\
\hline 7 & Very strong or demonstrated importance & $\begin{array}{l}\text { An activity is favoured very strongly over another; its } \\
\text { dominance demonstrated in practice }\end{array}$ \\
\hline 8 & Very, very strong & \\
\hline 9 & Extreme importance & $\begin{array}{l}\text { The evidence favouring one activity over another is of } \\
\text { the highest possible order of affirmation }\end{array}$ \\
\hline $\begin{array}{l}\text { Reciprocal } \\
\text { of above }\end{array}$ & $\begin{array}{l}\text { If activity } i \text { has one of the above nonzero numbers } \\
\text { assigned to it when compared with activity } j \text {, then } \\
j \text { has the reciprocal value when compared with } i\end{array}$ & \\
\hline Rationals & Ratios arising from the scale & $\begin{array}{l}\text { If consistency were to force by obtaining } n \text { numerical } \\
\text { values to span matrix }\end{array}$ \\
\hline
\end{tabular}

\section{METHODOLOGY}

\section{A. AHP Framework}

Step 1 to step 5 below explained about the application of AHP method.

Step 1. Set up a hierarchy structure.

Step 2. Scaling the relative of data based on the judgmental scale in Table 1 and then construct a pair-wise comparison matrix, $A$. Let $A$ be $n \times n$ pair-wise comparison matrix.

$$
\begin{aligned}
& A_{n x n}=\left[\begin{array}{cccc}
A_{1} & A_{2} & \cdots & A_{n} \\
\frac{1}{a_{12}} & a_{12} & \cdots & a_{1 n} \\
\vdots & \vdots & \vdots & a_{2 n} \\
\frac{1}{a_{1 n}} & \frac{1}{a_{2 n}} & \cdots & 1
\end{array}\right] \begin{array}{c}
A_{1} \\
A_{2} \\
\vdots \\
A_{n}
\end{array} \\
& \text { sum }=\begin{array}{llll}
A & B & \cdots & Z
\end{array}
\end{aligned}
$$

where $A, B, \ldots, Z$ is the sum of its column and all diagonal element are 1.

Step 3. Set up the normalized pairwise comparison matrix, $N$. The sum of its column in the matrix $N$ is equal to 1. 


$$
\begin{gathered}
N=\left[\begin{array}{cccc}
\frac{1}{A} & \frac{a_{12}}{B} & \cdots & \frac{a_{1 n}}{Z} \\
\frac{1}{A a_{12}} & \frac{1}{B} & \cdots & \frac{a_{2 n}}{Z} \\
\vdots & \vdots & \vdots & \vdots \\
\frac{1}{A a_{1 n}} & \frac{1}{B a_{2 n}} & \cdots & \frac{1}{Z}
\end{array}\right] \\
\operatorname{sum}=1
\end{gathered}
$$

Step 4. Calculate the weight for each criterion and alternative by averaging across its row of matrix $N$. Let the relative weight for the above comparison be, $W=W_{1}, W_{2}, \ldots, W_{n}$.

Step 5. Determine Consistency Ratio $(C R)$ by using Relative Index (RI) in Table 2. $C R=\frac{C I}{R I}$ where Consistency Index, $\quad C I=\frac{\lambda_{\max }-n}{n-1} \quad$ and $\lambda_{\max =} A\left(W_{1}\right)+B\left(W_{2}\right)+\ldots+Z\left(W_{n}\right)$.

Table 2. Relative Index (RI)

\begin{tabular}{|c|c|c|c|c|c|c|c|}
\hline $\mathrm{n}$ & 2 & 3 & 4 & 5 & 6 & 7 & 8 \\
\hline $\mathrm{RI}$ & 0.0 & 0.5 & 0.9 & 1.12 & 1.24 & 1.32 & 1.41 \\
\hline $\mathrm{n}$ & 9 & 10 & 11 & 12 & 13 & 14 & 15 \\
\hline $\mathrm{RI}$ & 1.45 & 1.49 & 1.51 & 1.48 & 1.56 & 1.57 & 1.59 \\
\hline
\end{tabular}

The pairwise comparisons are consistent if $C R<0.1$.

\section{B. Condorcet Voting Theory Based on AHP Method Framework}

In the previous section, the judgmental scale from Table 1 is used to construct the pairwise comparison matrix. However, in the framework of the Condorcet-AHP method, the scaling and the pairwise comparison matrix is constructed by using the method as follows (Bhattacharya \& Raju, 2017).

The importance of criteria is compared pair wisely with respect to the objective to evaluate their weight. Consider a project selection problem with 3 existing criteria from $X$ voters where Criterion $1=C_{1}$, Criterion $2=C_{2}$ and Criterion $3=C_{3}$. Table 3 shows the comparison between
Criterion 1 and Criterion 2. $X_{3}$ is eliminated from the computation since $X_{3}$ voters agreed that $C_{1}$ and $C_{2}$ are equally important. The same algorithm is applied when $C_{1}$ is compared with $C_{3}$ and $C_{2}$ is compared with $C_{3}$ pair wisely.

Table 3. Comparison of $\mathrm{C}_{1} \& \mathrm{C} 2$ Factor

\begin{tabular}{|l|c|}
\hline $\begin{array}{l}\text { Votes where C1 is given more } \\
\text { priority than C2 }\end{array}$ & $X_{1}$ \\
\hline $\begin{array}{l}\text { Votes where C2 is given more } \\
\text { priority than C1 }\end{array}$ & $X 2$ \\
\hline $\begin{array}{l}\text { Votes with equal priority to C1 } \\
\text { and C2 (eliminated from } \\
\text { count) }\end{array}$ & $X 3$ \\
\hline $\begin{array}{l}\text { Quantitative Ratio of C1:C2 } \\
\frac{X_{1}}{X_{2}}\end{array}$ & $a$ \\
\hline $\begin{array}{l}\text { Quantitative Ratio of C2:C1 }= \\
\frac{X_{2}}{X_{1}}\end{array}$ & $b$ \\
\hline Total Respondents & $X=X_{1}+X_{2}+X_{3}$ \\
\hline
\end{tabular}

Table 4. Pairwise comparison matrix

\begin{tabular}{|c|c|c|c|}
\cline { 2 - 4 } \multicolumn{1}{c|}{} & $C 1$ & $C 2$ & $C 3$ \\
\hline$C 1$ & 1 & $a$ & $c$ \\
\hline$C 2$ & $b$ & 1 & $e$ \\
\hline$C 3$ & $d$ & $f$ & 1 \\
\hline$\Sigma$ & $S 1$ & $S 2$ & $S 3$ \\
\hline
\end{tabular}

While, Table 4 shows the pairwise comparison generated using the quantitative ratio derived. The ratio of $C_{1}$ to $C_{3}$ is $c$ and the ratio of $C_{3}$ to $C_{1}$ is $d$. The ratio of $C_{2}$ to $C_{3}$ is $e$ and the ratio of $C_{3}$ to $C_{2}$ is $f$. Repeat Step $1-5$ of the traditional AHP framework to obtain the relative weight of criteria and alternatives for the project selection problems.

\section{DATA ANALYSIS}

A real-life empirical data on the factors that contribute to road accidents was used to demonstrate the application of Condorcet-AHP method. The data was collected by distributing a set of questionnaires to the respondents who are the policemen and firemen. The chosen criteria (car (c), 
lorry (l), motorcycle (m)) are the type of vehicles that most likely to get involved in a road accident. The alternatives for this case study (human behaviour factor (HB), environmental factor (ENF), engineering factor (EF)) are factors that contribute to road accidents.

Table 5 shows the relative weight and the ranking for alternatives using the AHP method.

Table 5. Relative weight and ranking for alternatives

\begin{tabular}{lcc}
\hline \multicolumn{1}{c}{ Alternatives } & Weight & Ranking \\
\hline Human behaviour & 0.3635 & 2 \\
Factor & & 1 \\
Environmental & 0.4457 & 1 \\
Factor & 0.1908 & 3 \\
Engineering Factor & \\
\hline
\end{tabular}

Table 6 shows the relative weight and the ranking (Rank) for alternatives using the Condorcet-AHP method. The final relative weight of criteria, $W_{c}=(0.4947,0.2103,0.2950)$ and the final relative weight of alternatives respect to each criterion, $\quad W_{A}=(0.4425,0.3438, \quad 0.2137$; 0.3954,0.5202,0.0844; 0.3096,0.5804, 0.1100).

Table 6. Ranking for alternatives using Condorcet-AHP method

\begin{tabular}{|l|c|c|c|c|c|}
\cline { 2 - 6 } \multicolumn{1}{c|}{} & \begin{tabular}{c}
$\mathrm{c}$ \\
\multicolumn{1}{c|}{}
\end{tabular} & $\begin{array}{c}\mathrm{l} \\
\mathrm{0}\end{array}$ & $\begin{array}{c}\mathrm{m} \\
\mathrm{N}\end{array}$ & Weight & Rank \\
\hline HB & 0.4425 & 0.3954 & 0.3096 & 0.3934 & 2 \\
\hline ENF & 0.3438 & 0.5202 & 0.5804 & 0.4507 & 1 \\
\hline EF & 0.2137 & 0.0844 & 0.1100 & 0.1559 & 3 \\
\hline
\end{tabular}

\section{RESULT AND DISCUSSION}

\section{A. The Ranking of the Alternatives}

Table 7 shows the result of Analytical Hierarchy Process (AHP) and Condorcet-AHP (CVT) method which are focus on factors that caused road accident. The result shows that both methods give similar ranking for alternatives which is the most contributing factor to road accidents is environmental factor followed by human behaviour factor and engineering factor. However, the result is different from expert preference (Exp) where the most preferred alternatives to the least preferred one is human behaviour factor, environmental factor, and engineering factor respectively.

Table 7. Comparison of the relative weight for the alternatives

\begin{tabular}{ccccc}
\hline Alternatives & AHP & CVT & Ranking & Exp \\
\hline $\begin{array}{c}\text { Human } \\
\text { behavior } \\
\text { Factor }\end{array}$ & $\begin{array}{c}0.3635 \\
=\frac{277}{762}\end{array}$ & $\begin{array}{c}0.3934 \\
577\end{array}$ & 2 & 1 \\
\hline $\begin{array}{c}\text { Environmental } \\
\text { Factor }\end{array}$ & 0.4457 & 0.4507 & & \\
& $=\frac{201}{451}$ & $=\frac{169}{375}$ & 1 & 2 \\
$\begin{array}{c}\text { Engineering } \\
\text { Factor }\end{array}$ & 0.1908 & 0.1559 & & \\
& $=\frac{83}{435}$ & $=\frac{29}{186}$ & 3 & 3
\end{tabular}

\section{B. The Comparison Between AHP and}

\section{Condorcet-AHP Method}

The weight of the alternatives for both methods when compared to each other is slightly similar. Especially for the weight for the most contributing factor to road accidents which is environmental factor.

The result from Table 7 is then compared by using Mean Test. Listed below are the hypothesis regarding the test:

$\mathrm{H}_{\mathrm{o}}$ : There is no difference in the weight of alternatives.

$\mathrm{H}_{1}$ : There is difference in the weight of alternatives.

$$
\begin{aligned}
\bar{x}_{A H P}= & \frac{\frac{277}{762}+\frac{201}{451}+\frac{83}{435}}{3}=0.3333 \\
\bar{x}_{C V T}= & \frac{\frac{277}{762}+\frac{201}{451}+\frac{83}{435}}{3}=0.3333
\end{aligned}
$$

Since $\bar{x}_{A H P}=\bar{x}_{C V T}=0.3333, \mathrm{H}_{\mathrm{o}}$ is retained. Thus, there is similarity between the relative weight of alternatives using both methods. The result is possible even though the data scaling does not use the preference scale shown in Table 1. When the AHP algorithm is used, the sum of its column of a normalized pairwise comparison matrix is always equal to 1. The overall weight of the alternatives is also equivalent to 1. This ensure that the mean value is being equal to 0.3333 and supporting the conclusion. 
Table 8 below shows the comparison between these two methods.

Table 8. Comparison of AHP and Condorcet- AHP (CVT) method

\begin{tabular}{ccc}
\hline Factor & AHP & CVT \\
\hline $\begin{array}{c}\text { AHP } \\
\text { Framework }\end{array}$ & Yes & Yes \\
\hline Consistency & Yes & Yes \\
\hline & 9-point Saaty & $\begin{array}{c}\text { ratio-based } \\
\text { (Voting }\end{array}$ \\
Data scaling & Theory) \\
\hline Time Factor & Time consuming & $\begin{array}{c}\text { Less time } \\
\text { consuming }\end{array}$ \\
\hline
\end{tabular}

When the Condorcet-AHP method is applied, the consistency of the judgment can be determined using $C R=\frac{C I}{R I}$ since the AHP framework is used to find the relative weight of the attributes. This method is simpler, more efficient and less time consuming than the traditional AHP method since the quantitative ratio-based approach based on actual voting process is used instead of Saaty scale to construct the pairwise comparison matrix. Thus, this method is preferable than AHP method.

\section{CONCLUSION}

AHP is recommended by many researchers since it can be used easily to evaluate qualitative and quantitative data based on multiple conflicting criteria. However, Bhattacharya and Raju (2017), stated that AHP has a flaw of being totally dependent on the individual subjective judgment. Sometimes the decision maker(s) has difficulty in deciding the degree of importance of a criterion over another criterion.

Hence, it is desirable that by using the Condorcet-AHP method, the process of evaluating and selecting the best alternatives can be more efficient because this method only require the decision maker to vote among the two possible candidates. They can omit the part where they need to decide on how many likely more important one option over another. This ensure that the Condorcet-AHP method is simpler than the traditional AHP method since the decision maker(s) can avoid the scaling problems.

In conclusion, it can be concluded that Condorcet-AHP method can be used to solve the project selection problems. With the application of Condorcet-AHP method, the scaling and the establishment of a pairwise comparison matrix is relatively convenient.

\section{ACKNOWLEDGEMENT}

This paper is a work under Universiti Teknologi MARA (UiTM) Cawangan Negeri Sembilan. Special thanks to our colleagues in Universiti Teknologi MARA (UiTM) Cawangan Negeri Sembilan, families, and friends. 


\section{REFERENCES}

Amiri, M. P. 2010, Project selection for oil-fields development by using the AHP and fuzzy TOPSIS methods. Expert Systems with Applications, vol.37, pp. 6218-6224.

Bhattacharya, S. \& Raju, V. 2017, A Condorcet Voting Theory Based AHP Approach for MCDM Problems. Indonesian Journal of Electrical Engineering and Computer Science, vol.7, no.1, pp. 276-286.

Nowak, M. 2013, Project portfolio selection using interactive approach. Procedia Engineering, vol.57, pp. 814-822.

Ozdemir, M. S. \& Saaty, T. L. 2006, The unknown in decision making. What to do about it. European Journal of Operational Research, vol.174, pp. 349-359.

Saaty, R. W. 1987, The Analytic Hierarchy Process-What It Is and How It Is Used. Mathematical Modelling, vol. 9, no.3-5, pp. 161-176.

Saaty, T. L. 1990, How to make a decision: The analytic hierarchy process. European Journal of Operational Research, vol. 48, pp.9-26.

Saaty, T. L. 1994, Highlights and critical points in the theory and application of the Analytic Hierarchy Process. European Journal of Operational Research, vol.74, pp.426-447.

Saaty, T. L. 2008 Decision making with the analytic hierarchy process. International Journal of Services Sciences, vol. 1, no. 1, pp.83-98.

Saaty, T. L. \& Vargas, L. G. 2013, Decision Making with the Analytic Network Process: Economic, Political, Social and Technological Applications with Benefits, Opportunities, Costs and Risks. (C. C. Hillier, Frederick S. \& Price, Ed.) (Vol. 195). New York: Springer.

Vinod Kumar, N. \& Ganesh, L. S. 1996, An empirical analysis of the use of the Analytic Hierarchy Process for estimating membership values in a fuzzy set. Fuzzy Sets and Systems, vol. 82, no.1, pp. 1-16.

Young, H. P. 1988, Condorcet's Theory of Voting. American Political Science Review, vol.82, no. 4, pp. 1231-1244. 